\title{
A Comparative Study of Chinese and Western cultures under the Background of Internationalization and Diversification
}

\author{
Jinjun Wang \\ Shandong Foreign Trade Vocational College \\ Qingdao,Shandong, 266100 China
}

\begin{abstract}
There are scores of definitions of "culture", which shows the complexity of the concept of culture. To explain its connotation, there is a certain degree of difficulty. From literature recorded, the word "culture" had already appeared in two thousand years ago, the original meaning refers to the ancient emperors of sandwiches and enlightenment. "Culture" is borrowed from the Japanese; Japanese translated from Latin Cuhura, now it is the English Culture in the modern sense. The term "culture" is the middle of the 19th century was hired in anthropological writings. In 1871 British scientist Taylor in his book definition of "primitive cultures" to the next culture is "the whole complex includes knowledge, belief, art, law, customs and habits of any capacity and as a member of society, including the acquired."Later, the American sociologist, cultural anthropologist was supplemented with an amendment to increase the "kind" and "values." Culture is complex system architecture, which contains many components.
\end{abstract}

Keywords- Internationalization; Diversification; The Comparison of Chinese and Western Culture

\section{INTRODUCTION}

In the context of globalization, currently the most popular theory is that the Western cultural hegemony. On this view of cultural hegemony specific content is: in the process of globalization, with the increase contact with the world, output of Western culture is far greater than the output of developing cultures. In addition, these cultures are often with Western values, lifestyle and will structure, thus affecting the cultural choices and developing countries, and ultimately at the expense of developing the local culture, to achieve from the culture in the West to control the world's spiritual purpose. British scholar Tomlinson in his "cultural imperialism," a book that the theory of cultural imperialism can be converted to each other is including the following meaning. First is an information flow imbalance of media imperialism. The second is (American culture) the development and the challenges of modernity to the traditional culture with a threat to national identity and cultural identity; the third is both global capitalist consumer culture impact on traditional society. Wherein the unbalanced flow of information refers to the first in the world of information flow in the Third World, significantly more than the third world information flow to the first world. Therefore, the flow of culture, with the country's economic and political power is proportional. Cultural imperialist countries like the US, Japan and the UK are not flowing into their cultures, but out of that culture rather than cultural import export. Therefore, the US cultural imperialism is by its powerful media propaganda advantage, a large output of its values and ideology, his values and ideology imposed on the world, prompted countries integration with the United States beliefs and values, thus abandoning the native language, traditions and culture. [4] 2 and cultural hegemony on the contrary, the postmodernist cultural hegemony of the process of globalization and integration on the trend poses a severe challenge, postmodernists have profound understanding of the mechanistic view of the world crisis. Mechanistic worldview of the world has a huge machine, which all things are determined by the initial conditions, and these conditions can be accurately plotted principle. In such a world, the chance has no effect. However, the latest scientific research and social development of the past two decades has proved that with this idea to look at nature and society, many phenomena cannot be explained. In today's world, determinism, stability, and orderly, balanced, progressive and Category linear relationship are increasingly useless, on the contrary, an important role in a variety of unstable and uncertain, non-continuous, disorderly, breaks and mutations are paid attention to by more people.

\section{COMPARISON OF CHINESE AND WESTERN CIVILIZATION IS ESSENTIALly COMPARING TwO SYSTEMS}

Why do not you say something to use comparison of Chinese and Western cultural comparison? I think with the name of the West, it has its own rationality. First, from the lateral view, it is standing on their own position by comparing either the West or the Chinese people; the two sides formed by this comparison will help understand the differences between their culture and other cultures, and not the other comparison to the country's people. Secondly, from a vertical perspective, the development of human history dictates. The ancient civilization of human civilization is divided into six zones: Chinese civilization, Indian civilization, Mesopotamia civilization, the Egyptian civilization, Greek civilization, the Maya civilization. Greek civilization and the history of the Mayan civilization have become living fossils, while the Mesopotamian civilization and Greek civilization constitute the matrix of Western civilization. Indian civilization still exists, but in China, it was introduced to China during the Han Dynasty, Chinese Confucianism as the main body of civilization has been 
accepted and transformation. From the Tang Wang Wei's "poem in paintings, painting in poetry" of Zen, the Song and even formed a Zen, Pure Land Buddhism, Weizhizhong, Tiantaizong, Huayanzong dominated by eight large Buddhist sects, also from China incoming Korea, east Fuso. We can say that Buddhist and Confucian civilization are closely linked and intertwined. They grow with local Chinese Taoist culture together that constitute a profound connotation of Chinese culture. Therefore, talking about Chinese culture is bound to involve Buddhist civilization to Western formulation; we just summarize a comparison of all the different civilizations, without further highlighting comparison of Western India. However, we should note that this comparison is limited to the macro-general, and specifically the microscopic comparison involves specific comparison between different civilizations, not available in Western generalizations.

In China it is a beyond ideology, beyond time and space. Scope is for many descendants of the issues of common concern. Whether in the late feudal society, in the semicolonial and semi-feudal period of residence, after the founding of New China, in terms of the mainland, Hong Kong, Taiwan, Chinese and western culture have set off a wave bursts, especially in moments of social change. Now, with the acceleration of the reform and opening up, "peace and development" have become the theme of the times, and a complementary blend of Chinese and Western cultures will become a trend, a wave of Chinese and western culture is likely to re-emerge. How, under the new situation, to carry out Chinese and Western culture from a higher level is worth comparing theoretical reflection. First, it is from the perspective of Chinese and Western body reflection and comparison. Chinese and western culture bodies are more of Chinese and Western culture itself, the nature and characteristics of knowledge. Comparing this knowledge depends on the concept of comparators. Because these two different shades of awareness and understanding of different cultures, to a certain extent, determine the comparison's epistemology and methodology. From the history of western culture, we can clearly see the development context.

Since the formulation and comparison of Chinese and western culture are feasible, the following will enter the operational level. American scholar Mr. Zhang Longxi has a wonderful exposition: " commentators emphasizes EastWest cultural differences, they are often sweeping, with one or a certain number of representatives of all the characteristics of a culture and the nature of that culture, sentence the East, and then the word has summed up the West, and always put things cultures against each other. I have many places in this book that cited examples of cultural opposition, and made myself a different view. To expand the comparative study of east and West, we must first overcome the tendency of different cultures mechanical opposition to seek common ground between East and West. Only on this basis, seeking the same in different, and they see the differences in the same, a comparative study was able to set up. " Indeed, if you take a fork and chopsticks for comparison, you should only see their differences. The real cultural comparison should be with the divergent or different in seeking common ground, just like comparison of the fork, Mucha, Tiecha, fork or chopsticks in wooden chopsticks, chopsticks and so on, which is precisely the difference between Mucha and Tiecha or chopsticks and chopstick between China and the West.

Cultural differences are due to differences between English and Chinese language and cultural differences in the types of Figurative Expressionism, it is mostly attributable to a different mode of thinking. Our former Ambassador to Germany is Lu Qiutian, the major Western thinking and cultural differences are summarized as four as follow. Asians stress integrity, while Westerners focus more on individuality; Asians pay attention seeking with thinking, while Westerners often pursue divergent thinking ; Asians Valuing Loyalty, while Westerners are more focused on principle; Asians express feelings indirect, subtle and emotional expression Westerners are directly exposed. He believes that the Eastern and Western Thinking differences are a nation in the long course of historical development, consciously or unconsciously, a fixed mindset to look at problems caused. $\mathrm{G}$ - Hofstede Ostend believes that Chinese people's way of thinking and Westerners do have differences: Chinese people are good at perceptual intuitive thinking, rational Westerners good logical thinking. Chinese people emphasize the overall things and Westerners pay more attention to the individual; Chinese people have thinking moral standard, Western scientific thinking places as the standard; Chinese people are thinking the track curves, rounded; Westerners trajectory is a straight line. This different way of thinking does affect the way they behave differently.

\section{DIFFERENCES BETWEEN CHINESE AND WESTERN CULTURES IN RESPONSIBILITY VIEW}

Although responsibility attribution model has a certain cultural universality, but the impact of cultural differences cannot be ignored. Currently, the two meanings of responsibility are expanding to include not only the attributed to negligence, but also the behavior of the positive outcome of attribution. Therefore, from the perspective of responsibility attribution and obligations of view, there are significant differences in the cultural backgrounds of the people of Western responsibility concept.

\section{A. Attribution Difference Inside and Outside}

It is also known as the qualities attributed to differences in the context of attribution. Chinese cultural background tends to put the responsibility of the individual events or behavioral outcomes attribute to external factors (external attribution or situational attribution), while Western cultural background tends to put the responsibility of the individual events or acts attribute to the results internal factors (internal attribution or trait attribution). Many foreign studies have found that the "East Asian culture tends to promote the observed behavior of external attribution; Westerners tend to make internal attribution". "Modern Western Attribution Theory to responsible behavior is mainly targeted at individuals; there are internal tendency trend doctrine, which focuses on attribution theory and East behavior entire 
background, of the so-called doctrine of Situation or background contrast."

\section{B. Differences in Terms of Values}

Anglo-American countries are with individual values at the core, while the Chinese cultural values reflect mass culture, group interests are above personal interests, Chinese traditional culture is with Confucianism as the core, the importance of spiritual study. Chinese culture advocates Heaven unity, advocating moderation, is China's ancient thinker repeatedly discussed culture; its basic theme is the relationship between human nature and society between people. this concept shackled to play individual initiative of the West's traditional culture individual-centered, individualistic Westerners most respected personal qualities, is a manifestation of cultural values of Western society, they worship the personal struggle and success that depends on the person.

\section{THE IMPACT OF CULTURAL DiFFERENCES ON BRITISH AND AMERICAN LITERATURE TRANSLATION}

The most common strategy is to translate domestication and alienation. An American scholar first proposed domestication and alienation concept in 1995. And his thought is affected by the point of view of the German philosopher and classical linguist. Translation has only two ways, it does not mean the translator does not bother author and do let the reader may move closer to the author. The translator is to try not to disturb the reader, so that readers of the closer" which is to see a translation is naturalized or Alienation translation that depends entirely on the reconstruction of cultural forms, translating to get production and sales in the form. What is the naturalization or alienation only while taking into account the change in the relationship between the value of the target language and culture in order to get to define the situation?"Ge Xiaoqin said:" The current in the pair 'naturalization' has awareness of the problem; the translation industry colleagues should distinguish naturalized two-premise law. First naturalization is under the principle of loyal; naturalization is under the premise that has two nonprescriptive loyal former general, the latter is descriptive; the former is primitive-centered theory, the latter is the target language and cultural orientation of the target language. "Domestication and alienation was not antagonistic, absolute return and absolute alienation does not exist. Domestication and alienation are relative, whether naturalized or alienation, translation methods will appear each other coverage, domestication and alienation have only two directions, their level of detail varies with the proportion of translation methods that are different, different strategies tendencies. Naturalization is the way translation, of replacement, interpretation, alienation technique is transliteration, literal and comments. Domestication and alienation are not opposites; they complement each other for different translation purposes. For example, Mr. Zhang Guruo mentioned "Tess," the translation of the original is in order to enhance the reader's understanding of translation, with literal way, but with a footnote describes the customs of England to help readers better understand the history and culture of the original background. Many scholars are using multiple translation naturalized complementary alienation, alienation and domestication in cultural translation process is moderate. Moderate naturalization enhances readability translation, alienation modest increases readers' understanding of the source language culture, strengthens cultural exchanges, the key to literary translation is diverse complementary.

\section{CONCLUSIONS}

In this paper, the structure of the cultural system will be divided into three levels, namely, material culture, institutional culture and spiritual culture. Then based on the contents of the hierarchy, it discusses cultural differences in performance and analyzes the reasons. It refers to the spiritual and cultural relations and human understanding of the subjective and objective means of self-improvement and value realization, including philosophy, art, ethics, customs, and religion and so on. Differences in performance on the Western way of thinking have many aspects, such as the difference between concrete and abstract, which reflected in the attitude to life that considered Westerners focus on practical, unreasonable, speaking shape; Chinese people have much emphasis on spiritual experience, intercede, and interest. In addition, China attaches importance to grasp things as a whole, rather than the West to study separate from the intricately linked thing. Western culture exists a huge difference, but it is also the formation of a certain culture contend with. This paper compares the western culture through discusses the differences in performance, analyzes the reasons reflecting the cultural genes of different nationalities. Of course, such studies should be included in cross-cultural communication and language acquisition in order to play a greater role.

\section{References}

[1] Deng Xiaomang. Teach culture, learning and reflection - a little commentary Weiming western culture method [J] Social Sciences, Jilin University, 2003,05: 55-61.

[2] Zhao Youbao. Western culture and social change in modern China [J] Central Plains Journal, 1989, 05: 115-118.

[3] Lu Baoan. On Yan Fu Evolution philosophy and western culture will pass [D]. Beijing Language and Culture University, 2008.

[4] Liu Dan. Independent college western culture bilingual teaching strategies [J] Henan Agricultural, 2014,12: 15-16.

[5] Gao Jun. Relatively high penetration of Chinese and Western military [J] art teaching in Guangxi Education, 2013,42: 93.

[6] Wang Honggang, Tang Zhigong. Language, Thought and western culture $[\mathrm{J}]$ Shenyang University of Technology (Social Sciences), 2010, 01: 94-96.

[7] Chen Biyun, Li Xiaoping. Comparative study, the responsibility of Chinese and Western concept [J] Psychological Exploration, 2008,01: $12-15$. 